\title{
Stabilization and recycling of contaminated marine sediments
}

\author{
Francesco Todaro ${ }^{1, *}$, Claudia Vitone $^{1}$, and Michele Notarnicola ${ }^{1}$ \\ ${ }^{1}$ DICATECh, Politecnico di Bari, 70126 Bari, Italy
}

\begin{abstract}
The paper deals with the treatment and reuse of submarine sediments, i.e. a relevant environmental issue due to the annual huge quantities of dredged sediments (over half contaminated) in Europe. In a vision of sustainability and circular economy, stabilization and solidification $(\mathrm{S} / \mathrm{S})$ treatments represent an interesting solution for both environmental protection and reuse of sediments in engineering works. The investigation involved polluted clayey sediments taken up to depths of about $1.5 \mathrm{~m}$ from the seafloor of the Gulf of Taranto (South of Italy). The research investigates the effects of a treatment with cement and lime enhanced by the addition of green additives, such as active carbon and biochar, for chemical remediation. The last one is a promising and cheap adsorbent material, that is the by-product of - mainly - agricultural waste pyrolysis. The first results suggest that appropriate mix designs and curing times could allow the reuse of sediments by both improving their geotechnical characteristics and making them environmentally acceptable in accordance to end-of-waste criteria.
\end{abstract}

\section{Introduction}

The continuous stream of sediments dredged, from harbours and waterways, is a considerable environmental issue recognized worldwide. Every year about 200 million of $\mathrm{m}^{3}$ of sediments are dredged only in Europe, over half contaminated and expensive to manage $[1,2]$.

In most cases, dredged materials are classified as waste, and disposed of with high environmental risks. Fortunately, this tendency has been changing in the recent years and there is a growing impetus for considering dredged sediments as a resource rather than waste. Conventions for the protection of the marine environment and some new European regulations concerning waste have been introduced to set guidelines for a proper management of dredged sediments, and to prioritize the reuse, recycling and recovering of sediments [3]. It follows that there is an acute need for technologies aiming to improve physical properties and hydro-mechanical behaviour of dredged sediments, allowing their possible reuse in the engineering field.

Among the management options, stabilization and solidification $(\mathrm{S} / \mathrm{S})$ can be, in some cases, the most economically and ecologically sustainable treatment $[4,2$, $5,6]$. It is based on adding cementing agents to dredged materials to improve their mechanical behaviour depending on the engineering problems to be solved [5]. In fact, the treated sediments can be recycled as aggregates for road construction [7], cemented mortars [8], fill material and blocks [9] or raw materials in brick production [10]. It follows that also the $\mathrm{S} / \mathrm{S}$ techniques can be different and vary depending on the targets to be reached by the treated sediments. The simplest form of sediment treatment is obtained by adding either cement or lime. Nevertheless, the effect of the treatment depends on several factors, such as the quantity of additive, the curing time, the composition and physical properties of the sediments, the pore-water chemistry. Also, if the sediments are polluted, the contaminants can interfere with the binders' chemistry, this compromising the effectiveness of the stabilization [11]. It follows that, for the optimisation of the sediments' reuse, other additives can be used (e.g. carbonaceous adsorbents) depending on the type of contaminants, physical properties and composition of the sediments and the desired performance to be obtained.

Only recently, there has been a growing interest in the use of biochar $(\mathrm{BC})$ as additive for $\mathrm{S} / \mathrm{S}$ treatments for various environmental applications. It is a by-product of thermochemical conversion, such as pyrolysis or gasification, of carbonaceous materials (i.e. biomasses and/or agricultural waste) in electric energy. The low-cost adsorbent is emerging as an economical substitute to the activated carbon, thanks to its several unique properties, which make it an efficient, cost-effective and environmentally friendly material for the contaminants' removal [12]. However, to the best of the authors' knowledge, there is a lack of knowledge concerning the effect of biochar and biochar-binder mixings on the geomechanical properties of sediments (Figure 1).

This study presents the first results of the experiments, that are still on-going in the Geotechnical Laboratory of the Politecnico di Bari [13] aiming to explore new alternatives for the sustainable management of contaminated marine sediments. In particular, the note presents the effects of treatments with traditional binders (i.e. cement or lime) and green additives (i.e. active

\footnotetext{
* Corresponding author: francesco.todaro@poliba.it
} 
carbon and biochar) on the geotechnical properties of the Taranto submarine sediments.

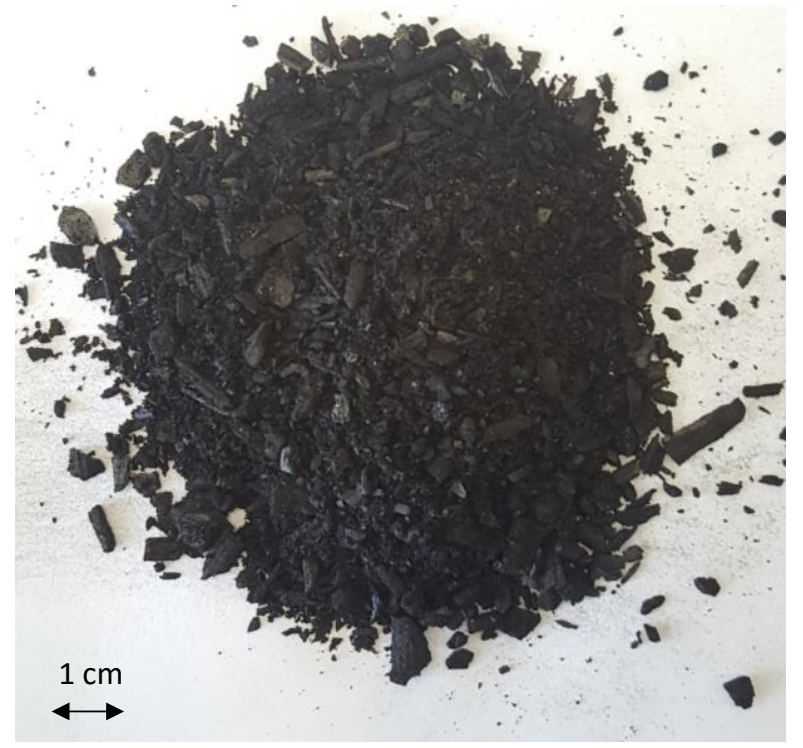

Fig. 1. Photo of the biochar used in this experiment.

\section{Materials and methods}

The samples of sediments were taken up to depths of about $1.5 \mathrm{~m}$ from the sea floor from the Gulf of Taranto (south of Italy), one of the most polluted areas in Europe, declared as "at high risk of environmental crisis" by the Italian government [14]. After being sieved through a 2 $\mathrm{mm}$ diameter sieve, the material was stored (inside plastic containers properly sealed) in a fridge at a temperature of $+4{ }^{\circ} \mathrm{C}$ until it was used for the tests.

The composition and physical properties of the sediments are reported in Table 1. The chemical characterisation of the samples showed that they were polluted by PAHs $(5840 \mu \mathrm{g} / \mathrm{kg})$, PCBs $(1510 \mu \mathrm{g} / \mathrm{kg})$, Mercury (1.99 mg/kg), Lead (91.41 mg/kg), Copper $(59.02 \mathrm{mg} / \mathrm{kg})$ and Zinc $(172.56 \mathrm{mg} / \mathrm{kg})$.

Table 1. Composition and physical properties of the sediments.

\begin{tabular}{|c|c|c|c|c|c|c|c|c|}
\hline $\begin{array}{c}\text { SF } \\
{[\%]}\end{array}$ & $\begin{array}{c}\text { MF } \\
{[\%]}\end{array}$ & $\begin{array}{c}\mathbf{C F} \\
{[\%]}\end{array}$ & $\begin{array}{c}\boldsymbol{\gamma} \\
{\left[\mathrm{kN} / \mathrm{m}^{3}\right]}\end{array}$ & $\begin{array}{c}\mathbf{G}_{\mathbf{s}} \\
{[-]}\end{array}$ & $\begin{array}{c}\mathbf{w} \\
{[\%]}\end{array}$ & $\begin{array}{c}\mathbf{e}_{\mathbf{0}} \\
{[-]}\end{array}$ & $\begin{array}{c}\mathbf{W}_{\mathbf{L}} \\
{[\%]}\end{array}$ & $\begin{array}{c}\mathbf{P I} \\
{[\%]}\end{array}$ \\
\hline 19 & 43 & 38 & 15.12 & 2.54 & 80.9 & 2.053 & 77.41 & 48.47 \\
\hline
\end{tabular}

Key in Table 1: SF, sand fraction; MF, silt fraction; CF, clay fraction; $\gamma$, total unit weight; $\mathrm{G}_{s}$; soil solid specific gravity; $\mathrm{w}$, water content; $\mathrm{e}_{0}$, void ratio; $\mathrm{w}_{\mathrm{L}}$ liquid limit; PI, plasticity index.

The sediments were treated by adding two different binders (i.e. CEM I 42.5 R Portland cement, C, and lime, $\mathrm{L}$ ) and different contents (by dry soil weight) of additives, namely active carbon (AC) and biochar (BC), to obtain the 6 mixings listed in Table 2.

Several specimens were prepared by thorough mechanical mixing of the slurry with the additives. All the materials were initially mixed for 5 min with a standard mixer and, then, a steel trowel was used to ensure a homogeneous paste. In the casting phase, the prepared mixture was inserted into different PVC molds and beaten to get rid of trapped air bubble.

The samples, in the curing phase, were kept at $20 \pm 5^{\circ} \mathrm{C}$ and $80 \%$ humidity (Figure 2).

Table 2. Mix designs used to treat the sediments. Key: Cement: C; Lime: L; Active Carbon: AC; Biochar: BC.

\begin{tabular}{|c|c|c|c|}
\hline Mixture & Binder (B) & $\begin{array}{c}\text { Additive } \\
\text { (A) }\end{array}$ & $\begin{array}{c}\text { B+A } \\
\text { content }\end{array}$ \\
\hline MIX_0 & - & - & $0 \%$ \\
\hline MIX_1 & C & - & $10 \%$ \\
\hline MIX_2 & C & AC & $15 \%$ \\
\hline MIX_3 & C & BC & $15 \%$ \\
\hline MIX_4 & L & - & $10 \%$ \\
\hline MIX_5 & L & AC & $15 \%$ \\
\hline MIX 6 & L & BC & $15 \%$ \\
\hline
\end{tabular}

The quantities of traditional binders (i.e. cement and lime) and green additives (i.e. active carbon and biochar) used for the geomechanical investigation have been defined after having verified their efficacy as environmental remediation solution [15].

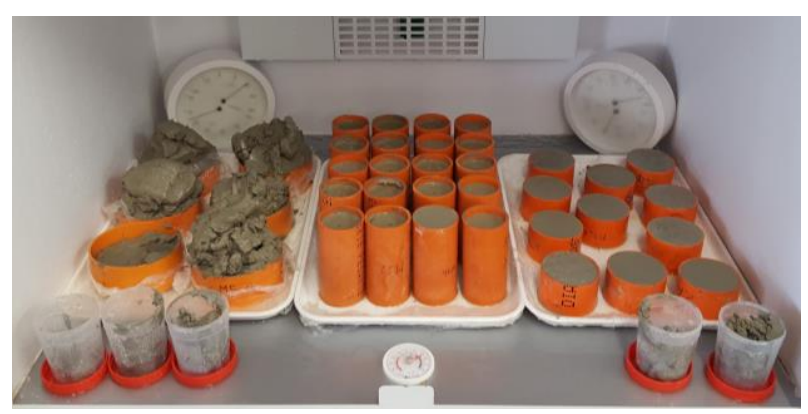

Fig. 2. Specimens prepared and placed in a temperaturecontrolled room with $80 \%$ humidity.

As reported in Table 3, together with the chemical tests, the geotechnical testing programme, that is still on-going, includes both physical and mechanical investigations on the sediment mixtures after different curing times (i.e. 14 and 28 days).

Table 3. Experimental testing programme.

\begin{tabular}{lccc}
\hline \multirow{2}{*}{ LABORATORY TESTS } & \multicolumn{3}{c}{ CURING TIME } \\
\cline { 2 - 4 } & $1 \mathrm{~h}$ & $14 \mathrm{~d}$ & $28 \mathrm{~d}$ \\
\hline Particle-size analysis & $\checkmark$ & & $\checkmark$ \\
\hline Liquid and plastic limits & $\checkmark$ & $\checkmark$ & $\checkmark$ \\
\hline Specific gravity & $\checkmark$ & & \\
\hline Oedometer tests & & & $\checkmark$ \\
\hline Unconfined compression tests & & & $\checkmark$ \\
\hline Determination of pH and Eh & $\checkmark$ & $\checkmark$ & $\checkmark$ \\
\hline Leaching tests & & & $\checkmark$ \\
\hline
\end{tabular}




\section{Results and discussion}

\subsection{Effects of stabilization on composition and physical properties of the sediments}

Figure 3 shows the grading fractions of both untreated and treated sediments after 28 days of curing. In general, it can be observed that the untreated sediments have a significantly higher clay fraction, $\mathrm{CF}$, than the treated ones. This is consistent with the creation of an open flocculated structure with clay-binder clusters interspersed by large voids [16]. For the mixtures with cement or lime, the test results show a decrease in clay fraction, $\mathrm{CF}$, and an increase in sand fraction, SF. This effect is more accentuated for the cement-treated sediments (MIX_1, MIX_2 and MIX_3) and, in particular, for those incorporating $\mathrm{AC}$ as green additive (MIX_2: $\mathrm{CF}_{\mathrm{MIN}}=13 \%$ and $\mathrm{SF}_{\mathrm{MAX}}=31 \%$ ). All the samples treated with lime (MIX_4, MIX_5 and MIX_6) have similar composition $(\mathrm{CF}=22 \% ; \mathrm{MF}=57 \%$; $\mathrm{SF}=21 \%)$, i.e. the use of green additives is not influencing the limetreated soil composition.

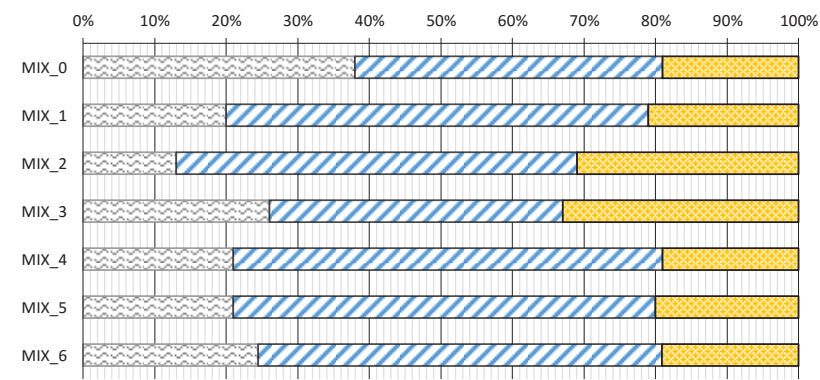

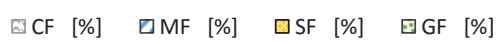

Fig. 3. Grading fractions of both untreated and treated sediments after 28 days of curing. Key: CF, clay fraction; MF, silt fraction; SF, sand fraction; GF, gravel fraction.

The Casagrande's plasticity charts in Figure $4 a$ and $4 b$ show the effects of the treatments on the Atterberg limits for the cement and lime-treated sediments, respectively. For each mix design, the plasticity points have different colour and the symbol sizes are proportional to the curing times (i.e. 0,14 and 28 days).

The first consideration that can be made is that, although the untreated sediments are $\mathrm{CH}$ soils according to USCS classification [17], the after-treatment material is classified as $\mathrm{MH}$ soil, irrespective of the additive used. These results appear to be consistent with those, from the literature [5], relative to submarine sediments from the Mar Grande area in Taranto and treated with similar percentages of traditional binders. For the cement-treated sediments (Figure 4a), the increasing curing time makes the plasticity points move downwards and to the left in the chart (i.e. a reduction in both $\mathrm{W}_{\mathrm{L}}$ and PI is recorded). Similar results have been found when the green additives are used. Specifically, after 28 days of curing, the sediments treated with cement and biochar show the maximum effect on the soil plasticity indices. When lime is used, Figure $4 \mathrm{~b}$ depicts a milder reduction in the plasticity index if compared to the cement-treated sediments. Moreover, the data show that only the sediments treated with lime and AC appear to follow paths similar (i.e. both $\mathrm{W}_{\mathrm{L}}$ and PI reduce) to those recurrent for cement-treated sediments in Figure 4a.

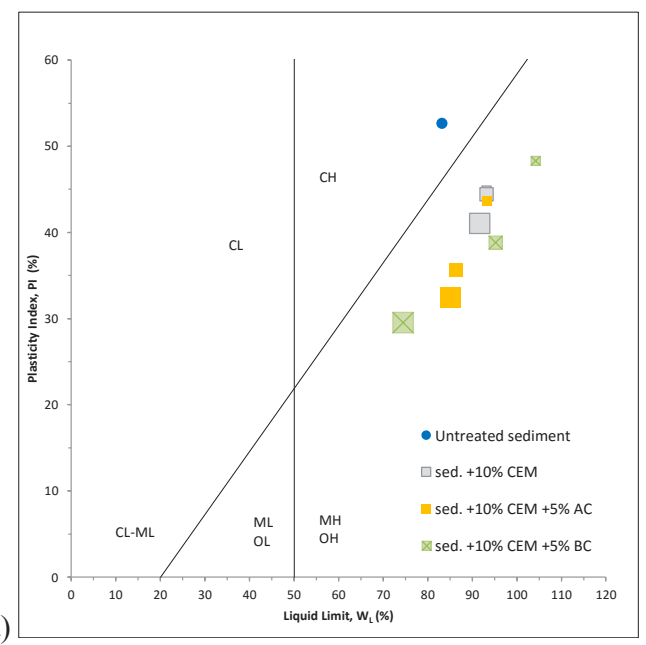

a)

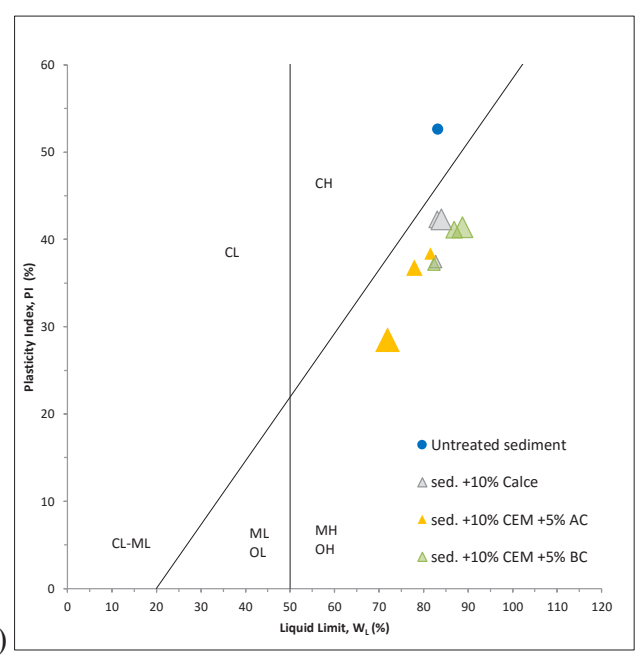

Fig. 4. Plasticity paths of cement (a) and lime (b) treated sediments. Symbol sizes are proportional to curing time (i.e. small symbols: 0 days, medium symbols: 14 days, large symbols: 28 days).

\subsection{Effect of stabilization on one-dimensional compression behaviour}

Figures $5 \mathrm{a}$ and $5 \mathrm{~b}$ show the results of the oedometer tests carried out on the untreated sediments and on the specimens stabilized with cement and lime after 28 days of curing, respectively.

Irrespective of the typology of the additives used, the compression curves of the stabilised sediments always lie to the right of the compression line of the untreated sediments in the void ratio, e - vertical effective stress $\left(\sigma^{\prime}{ }_{v}\right)$ plot. It is evident that, because of the cementation, treated sediments are more stable at higher void ratios than untreated ones, under the same consolidation pressure. Moreover, the data suggest that the use of green additives is not influencing the effect of stabilization on the one-dimensional compression behaviour: when either $\mathrm{AC}$ or $\mathrm{BC}$ are added, the compression curves are almost 
the same as those of specimens treated only with cement or lime. As expected, the cement-treated sediments, exhibit the higher values of vertical effective stress at yield: $\sigma_{\mathrm{y}}^{\prime}=500 \mathrm{kPa}$ for cement-treated sediments and about $100 \mathrm{kPa}$ for lime-treated ones.

a)

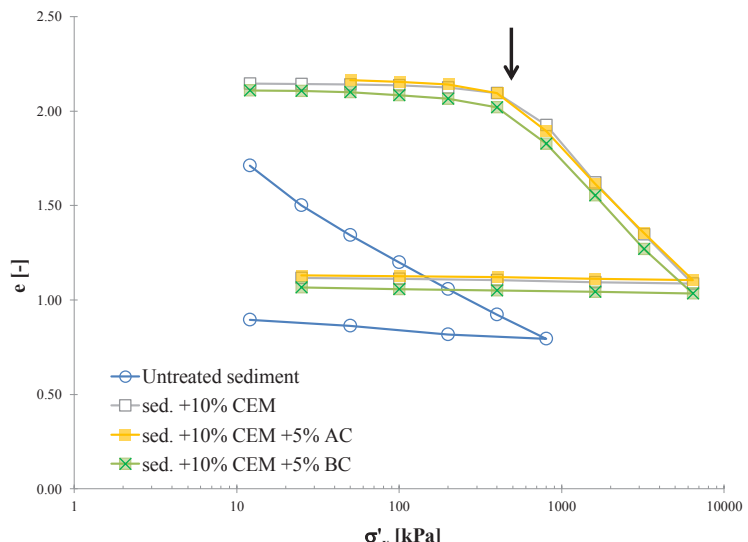

b)

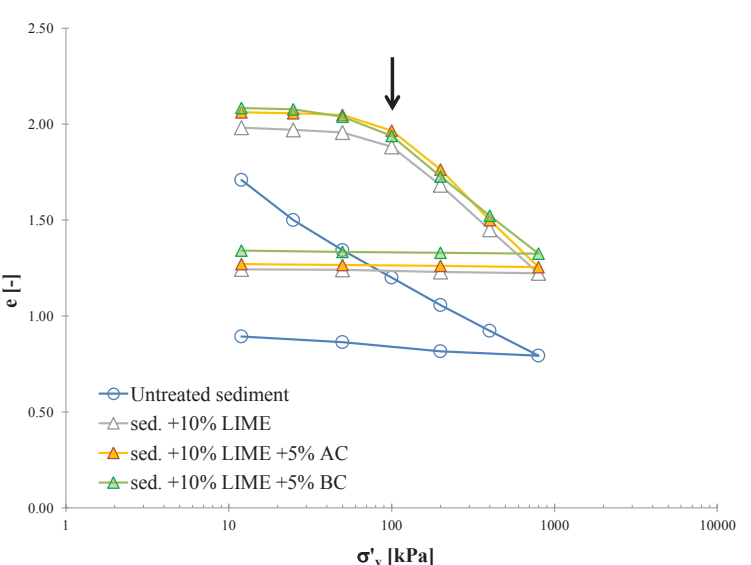

Fig. 5. Treatments with a) cement or b) lime and effect of green additives (i.e. active carbon, $\mathrm{AC}$, and biochar, $\mathrm{BC}$ ) on one dimensional compression behaviour (curing time: 28 days) of the submarine sediments.

The experimental results from this study show that, as expected, the compression behaviour of all the treated clay specimens here of reference appears to be always similar to that of natural unfissured clays. In particular, irrespective of the type and percentage of additive used, after 28 days of curing the Normal Compression Line (NCL hereafter) of the treated clay is located on the right of the ICL (Figure 6). This because the pozzolanic reactions induced by the treatment bring about a chemically induced structure.

If the results are included into the framework of behaviour in Figure 6, it can be concluded that the treated clays, as the natural unfissured ones, enter the structure permitted space as recalled by Leroueil and Vaughan [18]. This space is associated to values higher than one of the Stress Sensitivity ratio, i.e. $S_{\sigma}=\sigma_{\mathrm{y}}^{\prime} / \sigma^{*}{ }_{\mathrm{e}}$ (where $\sigma_{\mathrm{y}}^{\prime}$ is the vertical effective stress at yield and $\sigma^{*}$ is the equivalent effective stress on the Intrinsic Compression Line, ICL, at the same void ratio, Figure 6) that has been introduced by Cotecchia \& Chandler [19] to quantify the additional strength conveyed by the unfissured, natural soil structure (i.e. the combination of fabric and bonding) with respect to the same clay when reconstituted in the laboratory (i.e. $\mathrm{S} \sigma>1)$. Values lower than one are typical of undersensitive clays, such as fissured clays [20 - 22], where the combination of fissuring with the clay microstructure was found to weaken the clay in comparison with the same clay when reconstituted.

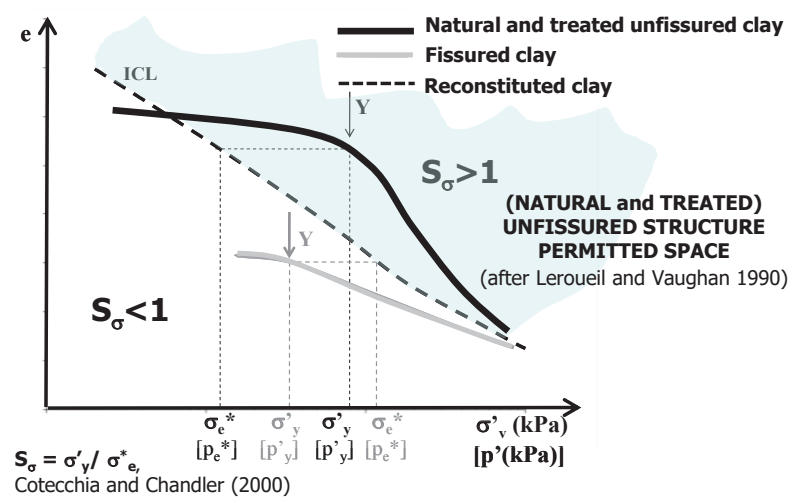

Fig. 6. Framework of compression behaviour of natural clay (fissured and unfissured), reconstituted clay and treated clay (after Vitone and Cotecchia 2011, modified).

The average recompression index $\left(\mathrm{C}_{\mathrm{r}}\right)$, is about 0.01 for cement-treated sediments and 0.03 for lime-treated ones, whereas the compression indices $(\mathrm{Cc})$ are equal to, on average, 0.8 and 0.4 , respectively.

The values of the coefficient of permeability, $k$, of the untreated and treated sediments are plotted in Figure $7 \mathrm{a}$ and $7 \mathrm{~b}$ against void ratio. They have been computed according to the consolidation theory by Terzaghi [23], in both oedometer loading and unloading phases. The data during loading show that the untreated sediment has slightly larger permeability (for the same void ratio) than that treated with cement. The permeability values do not seem to change when lime is used. Moreover, the presence of the additives does not change the permeability of the treated soil.

For all the specimens treated with cement, $\mathrm{k}$ in loading varies between $1.5 \mathrm{E}^{-9}$ and $3.4 \mathrm{E}^{-13} \mathrm{~m} / \mathrm{s}$ and, in general, it decreases with void ratio after yield stress (Figure 7a). In unloading, $\mathrm{k}$ is always lower than that in loading and it seems not to vary with the unloading phase. For all the specimens treated with lime, $\mathrm{k}$ in loading varies between $7.7 \mathrm{E}^{-10}$ and $1.0 \mathrm{E}^{-11} \mathrm{~m} / \mathrm{s}$ (Figure $7 \mathrm{~b}$ ).

Based on these figures, the following observations can be made: i) for low values of void ratio the $\mathrm{e}-\log (\mathrm{k})$ relationship is nearly linear, which implies that Taylor's [24] $\mathrm{e}-\log (\mathrm{k})$ relation can be applied to the treated sediments; ii) for the sediments treated with cement in unloading the $\mathrm{k}$ values reduce considerably and seem; iii) specimens treated with cement exhibit lower permeability than those treated with lime.

Moreover, the untreated sediments have similar permeability of sediment treated with lime. 

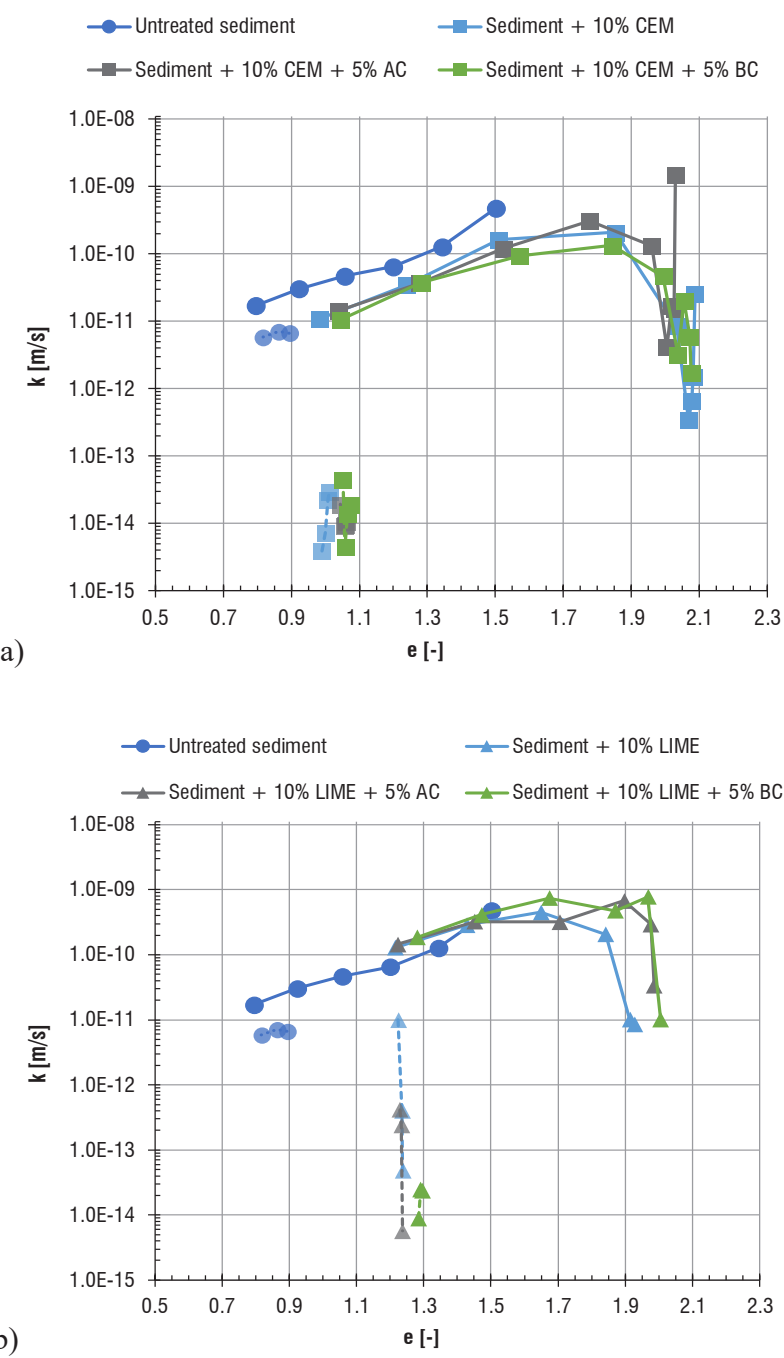

Fig. 7. Coefficient of permeability versus void ratio (data in loading and unloading); treatments with a) cement or b) lime.

\section{Conclusions}

This paper reports the first results of the geotechnical characterisation of contaminated submarine sediments treated with traditional binders (i.e. cement or lime) and green additives (i.e. active carbon and biochar). The laboratory experiments suggest the following:

1. The treated sediments have a significantly lower CF and higher SF than the untreated sediments. The use of green additives does not influence the treated soil composition when lime is used. Some changes are recorded, instead, for cement-treated materials.

2. The addition of traditional binders makes PI reduce and transforms the soil from $\mathrm{CH}$ to $\mathrm{MH}$, according to USCS classification. In particular, the effect of curing time on cement-treated sediments is a reduction of both $\mathrm{w}_{\mathrm{L}}$ and PI. The highest reduction is recorded by adding both cement and biochar, after 28 days of curing.

3. The oedometer compression curves of the treated specimens are located to the right of the untreated material in the void ratio, e - vertical effective stress $\left(\sigma^{\prime}{ }_{\mathrm{v}}\right)$ plane. This is because the traditional binders are inducing a chemical bonding and the cement-treated specimens exhibit the highest vertical effective stress at yield. The results also show that the use of green additives does not change the pattern of compression behaviour.

The results seem to suggest that the addition of either $\mathrm{AC}$ or BC does not significantly modify the behaviour of the sediments treated with lime or cement. Moreover, BC is a sustainable material (a recovered waste coming from the pyrolysis of biomass for energy generation) and it is much less expensive than to AC. However, further studies should deepen the mechanical effects of their use on submarine sediments. Since the biochar quality and performance vary significantly depending on feedstock types and pyrolysis conditions, future improvements in biochar development are also expected to centre around 'tuning' the properties for tailored applications.

\section{References}

1. SedNet, Dredging and Sediment Management European Sea Port, Proc. of the 7th International SedNet Conference, Italy, April 6th-9th, Venice (2011)

2. F. Todaro, S. De Gisi, M. Notarnicola, Proc ESEM, 3, 157-164 (2017)

3. Italian Ministerial Decree 173/2016, Regulation containing technical procedures and criteria for the authorization of seabed excavation materials at sea (in Italian), Italian Official Journal No. 208/2016 (2016)

4. S. Lirer, B. Liguori, I. Capasso, A. Flora, D. Caputo, J. Environ. Manage., 191, 1-7 (2017)

5. A. Federico, C. Vitone, A. Murianni, Can. Geotech. J., 52, 1-11 (2015)

6. G. Russo, A. Capotosto, P. Croce, G. Modoni, E. Vitale, Geotech. Engineering for Infrastructure and Development, 3, 1321-1326 (2015)

7. D. Wang, N. Abriak, R. Zentar, W. Xu, Env Tech, 33, 95-101 (2012)

8. J. Couvidat, M. Benzaazoua, V. Chatain, A. Bouamrane, H. Bouzahzah, Constru. Buil. Mater., 112, 892-902 (2016)

9. L. Wang, J. Kwok, D. Tsang, C. Poon, J. Hazard. Mater., 283, 623-632 (2015)

10. V. Cappuyns, V. Deweirt, S. Rousseau, Waste Manage., 8, 372-380 (2015)

11. D. Wang, N. Abriak, R. Zentar, W. Chen, Road Mater. Pavement, 14, 485-503 (2013)

12. F. Oliveira, K. Patel, D. Jaisi, S. Adhikari, H. Lu, S. Khanal, Bioresour. Technol., 246, 110-122 (2016)

13. F. Adamo, G. Andria, O. Bottiglieri, F. Cotecchia, A. Di Nisio, D. Miccoli, F. Sollecito, M. Spadavecchia, F. Todaro, A. Trotta, C. Vitone, Measurement, 127, 335-347 (2018)

14. C. Vitone, A. Federico, A. Puzrin, M. Ploetze, E. Carrassi, F. Todaro, Environ. Sci. Pullut. R., 23, 535553 (2016)

15. G. Barjoveanu, S. De Gisi, R. Casale, F. Todaro, M. Notarnicola, C. Teodosiu, J. Clean. Prod., 201, 391 402 (2018) 
16. S. Chew, A. Kamruzzaman, F. Lee, J. Geotech. Geoenv., Physicochemical and Engineering Behavior of Cement Treated Clays 130, 696-706 (2004)

17. ASTM, Standard practice for classification of soils for engineering purposes (2011)

18. S. Leroueil, P. Vaughan, Géotechnique, 40, 3, 467488 (1990)

19. F. Cotecchia, R.J. Chandler, Géotechnique, 50, 4, 431-447 (2000)

20. C. Vitone, F. Cotecchia, A. Federico, G. Viggiani. Italian Geot. J., 2, 7-29 (2018)

21. F. Silvestri, C. Vitone, A. d'Onofrio, F. Cotecchia, R. Puglia, F. Santucci de Magistris, in Geotechnical Soil Stress-Strain Behaviour: Measurement, Modelling, Analysis, The influence of meso-structure on the mechanical behaviour of a marly clay from low to high strains, 333-350 (2007)

22. V. Nardelli, M.R. Coop, C. Vitone, S. Chen, Géotechnique letters, 6, 205-210 (2016)

23. K. Terzaghi, Mathematish-naturwissenscha ftliche, Die berechnung der durchlassigkeitzifer des tones aus dem verlauf der hydrody namischen spannungserscheinungen (Vienna, 1923)

24. D. W. Taylor, Fundamentals of soil mechanics. John Wiley \& Sons Inc. (New York, 1948) 